\title{
Territorios de la familia. Propiedad y biopolítica en David Viñas
}

\author{
Family Territories. Property and Biopolitics in David Vinas
}

Territórios da família. Propriedade e biopolítica em David Viñas

\section{Marcos Zangrandi}

UNIVERSIDAD DE BUENOS AIRES/ CONICET, ARGENTINA

Doctor en Ciencias Sociales, Facultad de Ciencias Sociales, Universidad

de Buenos Aires. Máster en Comunicación y Cultura, Facultad de

Ciencias Sociales, Universidad de Buenos Aires. Ha publicado

diversos artículos y colaboraciones referidos a la literatura y la

cultura argentina del siglo XX, así como investigaciones sobre la

historia de Buenos Aires. Realizó la investigación, la compilación

y el estudio preliminar de Pedro Pago [seudónimo de David

Viñas]. Policiales por encargo (Ediciones de la Biblioteca Nacional,

2012). Correo electrónico: marcoszangrandi@gmail.com

Artículo de reflexión

Este artículo se elaboró en el marco de una investigación doctoral concluida recientemente y financiada por el Consejo Nacional de Investigaciones Científicas y Técnicas de Argentina (CONICET). Una versión sintética de este texto fue presentada en el IV Congreso del Centro de Letras Hispanoamericanas (CELEHIS), realizado en noviembre de 2011. Documento accesible en línea desde la siguiente dirección: http://revistas.javeriana.edu.co 


\section{Resumen}

A partir de las novelas Cayó sobre su rostro (1955) y Los dueños de la tierra (1958) de David Viñas, este trabajo indaga en una configuración correlativa entre la conquista del territorio patagónico y la imposición de una modalidad familiar, sexual y racial específica. Las dos narraciones trazan una relación necesaria entre la apropiación violenta de la tierra y los ordenamientos biopolíticos que emergen de este proceso. De este modo, Viñas interviene en el debate político cultural de fines la década de 1950 poniendo en discusión la legitimidad de un proyecto de país que se desmoronó con el peronismo.

Palabras clave: literatura argentina; familia; territorio; violencia

\section{Abstract}

From David Viñas' Cayó sobre su rostro (1955) and Los dueños de la tierra (1958), this paper investigates correlated configurations between the conquest of the Patagonian territory and the imposition of a specific sexual, racial and familiar form. Both novels, so, draw a necessary relationship between the violent appropriation and biopolitical orderings that emerge from this process. Thus, Viñas involved in the political and cultural discussion of late $1950 \mathrm{~s}$ and put into question the legitimacy of a project that collapsed with Peronism.

Keywords: Argentine literature; family; territory; violence

\section{Resumo}

A partir dos romances Cayó sobre su rostro (Caiu sobre o seu rosto, 1955) e Los dueños de la tierra (Os donos da terra 1958) de David Viñas, este trabalho investiga a configuração correlativa entre a conquista do território patagônico e a imposição de uma modalidade familiar, sexual e racial específica. As duas narrações traçam uma relação necessária entre a apropriação violenta da terra e os ordenamentos biopolíticos que emergem deste processo. Deste modo, Viñas intervém no debate político cultural de finais da década de 1950 colocando na discussão a legitimidade de um projeto de país que se arruinou com o peronismo

Palavras-chave: literatura argentina; família; território; violência

RECIBIDO: 1 DE MARZO DE 2014.ACEPTADO: 23 DE JUNIO DE 2014. DISPONIBLE EN LÍNEA: 01 DE JULIO DE 2015

\section{Cómo citar este artículo:}

Zangrandi, Marcos. "Territorios de la familia. Propiedad y biopolítica en David Viñas". Cuadernos de Literatura 19.38 (2015): 400-

413. http://dx.doi.org/10.11144/Javeriana.cl19-38.tfpb 


\section{Introducción}

Durante las décadas de 1950 y 1960 la narrativa argentina abrió dos líneas dominantes alrededor de la legitimidad y la propiedad como interpretaciones de lo que había significado el ingreso del peronismo en la vida argentina. Por un lado, las ficciones redundaron en torno a la figura de la vivienda (en tanto alegoría de la clase o de un proyecto de país) como umbral fracturado o como objeto de la destrucción, que se condensó alrededor de la figura de la "casa tomada" (Sebreli, 1964; Avellaneda, 1983; Gamerro, 2007). Otros escritores (Como Juan José Manauta, Ernesto Castro, Alberto Rodríguez [h.], Beatriz Guido y otros), en cambio, insistieron en el reparto ilegítimo y desigual de la tierra como debate pendiente en la construcción del país. No pueden pensarse los peligros que cercan la casa, parecía decir esta fracción, si no se debate acerca de quiénes son los dueños y cómo forjaron su construcción. Fue, dentro de este grupo, David Viñas (1927- 2011) quien intervino con mayor firmeza con sus novelas y relatos problematizando un territorio y correlativamente, un proyecto entrado en litigio simbólico luego de la alteración social, política y cultural vivida entre 1946 y 1955 .

El problema del reparto de la tierra es, sin dudas, uno de los ejes de la agenda de la izquierda europea y particularmente de la americana, de Marx a Mariátegui y de Bakunin a Emiliano Zapata. En la coyuntura local abierta en 1953 y en relación con la forma en que la literatura argentina comenzó a interpretar el peronismo, Viñas fue el beneficiario dilecto del debate abierto sobre la legitimidad del territorio. En efecto, durante el periodo 1946-1955, como nunca antes, se puso de manifiesto y polemizó sobre la estructura económico-social de la Argentina sostenida históricamente por la exportación de productos primarios y por una clase patricia favorecida por este modelo sin que esta visibilidad se haya traducido en una transformación radical de esa base (Torre, 2002).

Las novelas Cayó sobre su rostro (1955) y Los dueños de la tierra (1958) pueden verse de este modo, como ficciones que inician el debate sobre el problema de la legitimidad (un concepto vinculado tanto a la propiedad como a la familia) que se desprende de este proceso histórico. En ambos textos, vinculados por el hilo filial que une a los personajes centrales de las dos narraciones (Antonio y Vicente Vera), Viñas inscribió el dilema de la tierra ligado directamente a la imposición de un modelo familiar y racial que se impone contiguamente a una apropiación violenta. El debate así, se desplaza de la ciudad -espacio de la casa burguesa y del obrero industrial- y retorna al campo, base del montaje económico y social argentino. 


\section{Posesión de la tierra y gestión de la vida}

En su recorrido histórico que va desde la presidencia de Julio Roca (1880-1886) hasta el primer gobierno del radical Hipólito Yrigoyen (1916-1922) -período en el que se afirma y define la conquista de los territorios de la Patagonia y una modalidad agroexportadora integrada al sistema capitalista internacional-, las dos novelas de David Viñas subrayan la apropiación de la tierra que es congruente con una forma de poder y un tipo de sometimiento de un sujeto cíclicamente oprimido.

Es notable en este sentido, la manera en que se vinculan las imágenes de la tierra y de la vida en Cayó sobre su rostro. El relato nos lleva inicialmente al remoto pasado de Antonio Vera, el protagonista, durante una campaña militar en la frontera durante la guerra contra el indio a finales de la década de 1870, escenario fundacional del proyecto de país que se comienza a construir. Vera observa a Sosa, otro conscripto que tiene hundidos los pies en el agua estancada. Así como parece sumergido en el fango, Sosa está descrito como una bestia en los ojos de Vera, quien "le miraba los pies, los dedos tan largos como las manos y una orla de pelos alrededor de los tobillos" (Gayó sobre 17). También los demás conscriptos se asemejan a animales confundidos con el lodo: "todos los soldados estaban allí amontonados como esos dos sapos del otro lado del zanjón. Hasta parecían verdosos esos hombres, tan verdosos como el agua espesa del zanjón" (23). Todos esos cuerpos -reducidos a los requerimientos de la guerra- no son diferentes del territorio que será conquistado. Las percepciones de Vera ponen de manifiesto así, la continuidad necesaria entre la tierra y la bestialidad de esos hombres, cuyo destino no es sino la sumisión. Vera no se considera uno de ellos; él está por encima, dominará la tierra y los hombres que están en ella.

Es un día caluroso. Sosa y Vera se dirigen a una laguna para refrescarse. Vera observa escondido, el ataque furtivo de unos indios que matan a su compañero, desnudo y desprevenido. No hay ninguna denuncia: Vera se apropia del sueldo de Sosa y de las tierras que iban a entregarle como recompensa por su servicio. Este episodio subraya el vínculo entre la figura de la tierra subyugada con los hombres sometidos y derrotados. Para Antonio Vera, que encarna la voluntad del proyecto político liberal y modernizador que se instala en Argentina desde 1880. Los hombres que se encuentran figuradamente arriba dominan la tierra y en cambio quienes están adheridos a ella, sean soldados, indios u obreros, están dominados -mucho de ello tiene relación con los "hombres de a caballo", figura de la hombría y del poder a la que Viñas le dedicó una novela en $1968^{1}$-. Puede

1 Por ello el declive del caudillo, expuesto en las primeras páginas de la novela, es la de la caída del caballo por parte de Antonio Vera, ya viejo y solitario, quien queda ligado a la tierra, definitivamente hundido en ella, imagen que anticipa su muerte y el final de su dominio. 
verse en esos seres animalizados, confundidos con la tierra y reducidos a la vida desnuda, el reflejo de la aniquilación de los indios que en Cayó sobre su rostro aparece entre bambalinas. Bajo el orden de la república liberal, sus vidas están sometidas e igualadas a la conquista territorial.

La tierra ha de ser conquistada, los hombres exterminados y dominados. En este sentido, Gabriel Giorgi (2004), siguiendo la reflexión de Susan Buck-Morss, apunta que el Estado-nación moderno es primordialmente espacial y en consecuencia, su elemento principal de construcción es la frontera. La anexión de la Patagonia al mapa argentino sería así ejemplar respecto a este tipo de imaginación. Giorgi advierte asimismo que Viñas adiciona a esta conquista otra de tipo biopolítica, que implica la gestión sobre los cuerpos; en el caso de las acciones sobre las poblaciones patagónicas, su eliminación del territorio para la construcción del mapa, reflejado en la atroz imagen escolarizada como "conquista del desierto".

Bajo esta perspectiva puede advertirse una relación especular entre los grupos que son alternativamente la amenaza y el blanco de las elites. En el último cuarto del siglo XIX, ellos son los indios que delimitan la frontera sur del país; hacia las primeras décadas del siglo XX, los obreros, en buena parte inmigrantes, son los que ponen en peligro el orden social. Anota David Viñas en el ensayo Indios, ejército y frontera:

Los enemigos prioritarios en el nuevo siglo eran el obrero anarquista, el agitador social y el sindicato" [anota David Viñas en el ensayo Indios, ejército y frontera] [...] todos esos eran los que organizaban los malones rojos que ya no salían de Carhué o de las Salinas Grandes; las tolderías de 'la Sodoma del Plata' quedaban ahí nomás, en la Boca. Es que a lo largo de un cuarto de siglo se había producido la inversión de la dicotomía de Sarmiento. (115)

Ambientada en las huelgas patagónicas de 1920 y 1921 durante el gobierno de Yrigoyen, la narración de Los dueños de la tierra (1958) sitúa a la masacre de los obreros en el mismo espacio geográfico que las matanzas de los indios (la Patagonia), señalando con ello la relación ineludible entre uno y otro grupo exterminados y la persistencia del dominio violento de la tierra² ${ }^{2}$.

2 Sobre la apropiación de tierras y la muerte de indios por parte de los estancieros que en la novela ficcionaliza, ver el minucioso trabajo de Osvaldo Bayer en La Patagonia rebelde (1986). Es necesario destacar por otra parte, el papel destacado que el padre del escritor, Ismael Pedro Viñas, tuvo en aquel conflicto. Efectivamente, Osvaldo Bayer señala que Ismael Viñas se enfrentó inéditamente con el poder de los latifundistas, su mayoría ingleses: "Viñas -de extracción radical, amigo de Yrigoyen- rompió con la tradición de que todos los funcionarios y jueces patagónicos respondieran directamente a los intereses de los estancieros o fueran meros 
En las dos novelas Viñas redunda sobre el lazo que se traza entre la apropiación de la tierra con un cercenamiento étnico y sexual. Los dueños de la tierra se inicia con un episodio en el que se cruzan el exterminio de los indios y su castración post mortem (se paga a los cazadores por cada miembro sexual masculino). La escena se desarrolla en 1892, varios años después de la campaña de Roca, cuando los estancieros con sus subordinados armados realizan las tareas de aniquilación en el extremo sur argentino. Las comparaciones con animales se repiten: se habla de acorralar a los indios como a guanacos y como a lobos marinos; más adelante los disparos se mezclan con los gritos de los patos. La vida humana es equiparada a la animal, los hombres "cazan" y "faenan" un grupo de vidas despojadas de valor -a diferencia del ganado que más adelante enriquecerá a los estancieros-. El Estado es el promotor de la apropiación violenta de la tierra y de la tácita limpieza de los territorios, sin que haya algún impedimento; se legitima en este sentido, un escenario en donde ciertas vidas, dentro del orden económico hegemónico, cobran valor y otras son devaluadas al mínimo. "Todo era cuestión de presentar uno de esos formularios del Gobierno" -piensa uno de los estancieros mientras oye los tiros- "Después había que limpiarla" (14). Lo que por un lado implica el cercenamiento étnico, por el otro es castración y sometimiento sexual; "matar era como violar a alguien" -cavila uno de ellos- "había que correr, se podía gritar, se sudaba y después se sentía hambre" (11).

La cadena de apropiación se afirma sobre cuatro pilares: territorialidad, capitalismo, exterminio y dominio sexual. Antonio Vera, cuya construcción política remite a la figura paradigmática del caudillo en la novela latinoamericana, está sustentado en ellos: el soldado de las campañas contra los indios se convierte en dueño de inmensos campos en la región de Cañuelas, fuente de sus riquezas. Posee, asimismo, dominio sexualmente activo y excluyente sobre las personas que lo rodean. Durante los tiempos de la guerra mata con una excusa a un colega para quedarse con la que será su mujer, Consuelo. Pero también echa mano a

agentes de éstos. El juez Viñas iniciará, ante los sorprendidos ojos de los representantes de las sociedades anónimas, juicio por defraudación al fisco contra uno de los más poderosos establecimientos ganaderos: 'The Monte Dinero Sheep Farming Company'. También, el decidido juez Viñas iniciará juicio contra 'The San Julian Sheep Farming Company' por posesión indebida de los bienes de Donald Munro, fallecido a principios de siglo y cuyos campos, al no existir herederos, debían pasar al dominio del Consejo Nacional de Educación" (32). Su papel fue fundamental en relación con los derechos de los huelguistas en la primera etapa del conflicto. Sin embargo, según Bayer, después de los sucesos en la estancia "El Cerrito" a principios de 1921 (sangrientos enfrentamientos entre los huelguistas y la policía, además del secuestro de estancieros), el juez, asustado por el curso de la protesta, le escribió al ministro de Justicia para pedirle intervención militar (88). 
Mariquita, la mujer de su amigo Corti e inmediatamente la recluye en su casa. A Vera le deleitan tanto los placeres que le ofrece Mariquita como los que siente al humillar a Corti, tratándolo de apocado, cajetilla, de corta hombría -en los términos que la entiende Vera- o sencillamente como cornudo. El placer para Vera se centra en la posesión de ambos, en la mujer que se ríe de su dócil marido y en el hombre que se doblega al poder y no duda en decirle: "Usted es demasiado hombre, don Antonio" (91). Y si todo esto no sacia sus apetitos, ahí están todas las mujeres del burdel a su disposición.

Penetrar a una mujer, matar, poseer tierras, mandar: en todos los casos se domina y se somete. "Es macho Roca, muy macho" (17) comentan los soldados en la frontera, mientras eliminan indios. Antonio Vera los escucha: ese es su modelo. Se trata de una representación reiterada del caudillo latinoamericano en la que la hombría es edificante del poder ${ }^{3}$. De acuerdo con el escenario en que actúa y con sus costumbres, Vera también se vincula con el moreirismo: el bandido rural que a partir de la construcción del consenso social que convoca su figura, desafía el monopolio de la violencia del Estado sobre un territorio que disputa -Viñas ya había trabajado sobre un bandido rural en 1953: Mate Cocido- ${ }^{4}$. Cayó sobre su rostro construye a su protagonista como carácter intermedio entre esas dos figuras: el caudillo y el bandido. Sobre ellas, el poder territorial tiene que ver necesariamente con las variantes de los términos violar y castrar.

\section{Territorios de la familia}

La apropiación de la tierra y la conformación de la familia tienen un correlato directo en las narraciones de David Viñas. En Cayó sobre su rostro el mismo patrón rige para el dominio de la tierra y para la posesión de una mujer, arrebatada a otro soldado en los tiempos de la campaña. Esa mujer, Consuelo Ribas, provinciana y de pasado no del todo claro, tiene rasgos que Vera quiere para establecer su poder. Ella es blanca, rubia, descendiente de inmigrantes europeos y sabe leer; su aspecto reafirma la política étnica que se impone en la Patagonia. Eso le basta

3 Gabriela Polit Dueñas recorre en su trabajo Cosas de hombres (2008) la relación necesaria entre masculinidad, poder y escritura en la conformación de la figura del caudillo latinoamericano durante el siglo XX.

4 Viñas publicó Mate Cocido en 1953 bajo el seudónimo Pedro Pago en la editorial Vorágine. Un volumen reciente recoge las tres novelas sobre criminales argentinos que Viñas editó con ese nombre: Policiales por encargo (2012). La hipótesis sobre los bandidos rurales de Eduardo Gutiérrez las desarrolla Juan Pablo Dabove en su artículo "Eduardo Gutiérrez: narrativa de bandidos y novela popular argentina" (2010). Sobre la figura de Gutiérrez y la inscripción de su literatura en el siglo XIX, ver el trabajo de Alejandra Laera, El tiempo vacío de la ficción (2004). 
a Antonio Vera para elegirla y mantenerla a su lado. Esta apropiación remite al mito de las cautivas en el largo proceso de conquista de las tierras americanas. Efectivamente, las mujeres blancas capturadas por los indios eran, en el recorrido de las narrativas de la conquista - de Esteban Echeverría a Jorge L. Borges ${ }^{5}$, las imágenes de la virtud racial corrompidas por la barbarie; y en este mismo sentido, el cuerpo de la mujer se convertía a la vez en una pieza de valor y en una frontera móvil. Como lo señala Cristina Iglesia en su estudio sobre las cautivas en la cultura argentina (1987), la vuelta del Martín Fierro a la civilización se produce a partir del episodio de su encuentro con la mujer apresada y vejada por la tribu patagónica. Su gesto de retorno es también la inversión de la usurpación; ese regreso puede pensarse como la marca restauradora a partir de la cual, en las últimas décadas del siglo XIX, se llama a liberar a la mujer blanca. Viñas instala a Vera en este plan: su elección por Consuelo articula la conquista del territorio, la imposición racial y la apropiación del cuerpo de la mujer. El caudillo de Cañuelas de este modo, no solo traza líneas territoriales sino que correlativamente marca las fronteras biopolíticas.

En el juego de pasados y presentes de Cayó sobre su rostro son evidentes dos familias que ponen de manifiesto esa frontera pero también marcan las grietas de un modelo familiar (y en este sentido, de un proyecto político). Por un lado está la familia "gringa", "blanca" que conforma Vera junto a Consuelo y al hijo que tienen juntos, Vicente. Por otro, la familia "china", "ilegítima" que lo liga a la criada Isabel y al bastardo Gervasio. No hay solidaridad sino confrontación entre ambos grupos, alentada justamente por el padre. En particular, la narración marca una oposición entre los dos niños; uno criado en la virtuosa familia burguesa, el otro, un hijo de una sirvienta, extramatrimonial, negado por su padre; uno es blanco, el otro es mestizo. Ambos niños se conocen e inmediatamente se enfrentan. Antonio los observa mientras se pelean, respaldando a Vicente porque "se trataba de sí mismo, de quien él había elegido y apoyaba, de sus propias manos estiradas o prolongadas" (Cayó sobre 59) -y con ello el texto abona la teoría del cuerpo eterno del padre que se prolonga en el nombre y la sangre de sus hijos legítimos (Roudinesco 2010)-. Ese niño

5 Borges actualiza el mito de la cautiva en su cuento "Historia del guerrero y la cautiva", incluido en la colección El Aleph, de 1949, en el que refiere el encuentro con una mujer inglesa apresada por una tribu araucana que ha adoptado sus costumbres salvajes. En este relato sin embargo, la cautiva, asumida como bárbara, actúa -transita la frontera- de forma autónoma respecto de sus captores. La fecha de publicación de esta narración señala que en la puerta de la década de 1950, las imágenes de las cautivas, como nostalgia o como recuperación de los ejes culturales rosistas, se cruzaban con los debates propios de esta coyuntura. 
débil condensa todo un proyecto de conquista territorial y biopolítica. Pero al ver que Gervasio es más fuerte y hábil, Vera interviene directamente y le exige a Vicente que golpee a ese "chinito hijo de cualquiera" (6o). La dureza de la escena revela el sostén que para el caudillo implica cierto orden racial de la familia en relación con su dominio extramuros.

Un episodio posterior de la misma novela enfatiza este mismo aspecto que conecta legitimidad privada y poder público. Vicente Vera, el hijo virtuoso, ya es mayor y se enfrenta con Antonio cuando el primero se une al radicalismo, proyecto político de base popular opuesto a las convicciones del padre:

- ¡No puede ser! ¿Con el viejo Bernardo? ¡No sos hijo mío! ¡No sos hijo mío! $[\ldots]$

-No es don Bernardo, papá. Su padre lo miró con la quijada caída:

-¿Quién si no?

-Y se secaba las lágrimas.

-Hipólito [...]

- ¡Quién lo conoce a ése! ¡Un don nadie!... ¡Un hijo de su madre! (Cayó sobre 131-132).

Como se ve en este fragmento, Hipólito Yrigoyen, primera figura política que rompe el orden del liberalismo oligárquico, no tiene padre, es "hijo de su madre", aspecto que le quita, a los ojos del caudillo, toda validez, toda legitimidad. Esta es la imagen con la que se describe la democracia, liderada por un "guacho", por un "chino" -así ha señalado Antonio Vera a su propio bastardo-.

Esta esquemática oposición se vuelve más compleja cuando se confrontan los personajes de las dos novelas. En ese sentido es interesante ver las diferencias entre las mujeres que eligen los protagonistas de las dos ficciones de Antonio Vera (Cayó sobre su rostro) y Vicente Vera (Los dueños de la tierra), padre e hijo. Por un lado, Antonio valora positivamente la condición de mujer blanca de Consuelo, así como su sumisión y aires de señora, de acuerdo a las ambiciones del caudillo; por otro lado, la defenestra su supuesta robustez y debilidad. Antonio le impide además salir a pasear por Cañuelas -marcando el valor del encierro doméstico como enclave social virtuoso- y con ello el puente entre el mundo doméstico -estrictamente privado- y la figura pública de Vera. En particular, la concepción del cuerpo de la mujer en Cayó sobre su rostro remite a cierto imaginario del Medioevo europeo, según lo anota Roudinesco (2010), en tanto se lo equipara con la tierra parcelada, dominada y fértil sobre la que siembran y cosechan los hombres -una idea que suponía a la mujer como territorio por debajo del estándar humano y la presumía directamente ligada a 
la concepción $-{ }^{6}$. Sin dilatar el análisis en teorías de género, la novela de Viñas construye simbólicamente un paralelo entre la posesión de una mujer y la apropiación de la tierra como dos elementos recíprocos.

Diferente es el personaje Yuda Singer, la pareja de Vicente Vera (Los dueños de la tierra) en su misión mediadora en el conflicto entre obreros y patrones a principios de la década de 1920. Yuda, inmigrante rusa, es judía, culta, inteligente y desconfiada de las intenciones del gobierno de Yrigoyen. Vicente busca continuamente el equilibrio "neutral" que supone que el Estado ha de tener entre las exigencias de estancieros y trabajadores rurales. Yuda, en cambio, interviene permanentemente para mostrar las contradicciones del ideal del abogado y por extensión, de la política yrigoyenista. "Pertenecés a un partido de señoritos que se derriten por los verdaderos señoritos y que por otro lado se enternecen por los que están abajo" (173), lo acusa Yuda a medida que Vicente va descubriendo su fracaso. De igual forma, rechaza el lugar doméstico y social que tienen las mujeres como Consuelo Ribas: "usted es de los que quieren que las mujeres se muestren blanditas y sumisas. No quieren gallos, prefieren monos, monos blandos que no pongan resistencia" (121). Yuda no encaja en los moldes del orden doméstico burgués y en consecuencia, trazando nuevamente el paralelo entre mujer y tierra, si el de Consuelo era blanco y mórbido, Yuda define su propio cuerpo como, "una porquería" (126) que se escama por la psoriasis y que está marcado por la violencia que sufrió a causa de su condición de judía. Esa actitud discrepante se encarna en el cuerpo oculto de la mujer. En un pasaje de sutil erotismo, Yuda le muestra las cicatrices de las heridas de un pogromo que sufrió en Odesa, pidiéndole al abogado radical: "sé bueno conmigo" (139). El cuerpo de Yuda, por un lado, es el cerco privado de la disidencia pública, porque refuta el imaginario idílico de la privacidad burguesa. No hay aquí una mujer con pudores; no existe el imaginario de un cuerpo exuberante y lozano. La imperfección de Yuda es el testimonio vivo de la opresión que le reclama a Vicente que se enfrente a la imposibilidad de una mediación armónica. Asimismo, la figura de un cuerpo de mujer interrumpido, marcado y a la vez preñado, desafía la escritura: tangible y humana. Yuda es una mujer trazada -escrita- cuyas marcas denuncian un extramuros autoritario y exterminador y cuyo recorrido reúne grupos sistemáticamente perseguidos por los núcleos de poder: judíos, indios, obreros, disidentes? ${ }^{7}$ De la misma manera,

6 Algo de razón tenían en este sentido, las teorías feministas que la modernidad emancipó y les otorgó derechos a los varones, mientras que a las mujeres las mantuvo en una relación patriarcal y servil puertas adentro (Pateman 1996).

7 En relación con esta imagen Rita Segato (2004) apunta, reflexionando sobre la serie de femicidios en Ciudad Juárez durante los últimos años, que los actos de violencia sobre las mujeres 
el fracaso de la mediación de Yrigoyen frente a la oligarquía tiene un correlato familiar: Vera, Yuda y su futuro hijo tienen que salir de esta tierra dominada por los terratenientes, donde no hay mayor espacio (o territorio) para la rebelión.

Así, si el de Consuelo es un territorio blanco y dominado, el cuerpo imperfecto de Yuda es la imagen de la tierra sublevada y de los "bárbaros" que se resisten a doblegarse. Este personaje (Viñas lo advirtió más de una vez) lo construyó en diálogo con la figura de su madre, inmigrante rusa también que, según la leyenda que alimentaba el escritor, había venido en el mismo barco que el militante anarquista Simón Radowitzky. Efectivamente, su madre Esther Porter fue la primera imagen de la rebeldía para Viñas, aquella que se animaba a contradecir la normativa de los señoritos que la rodeaban, particularmente de su pareja, Ismael Pedro Viñas (padre de David). Al respecto, el escritor le contaba a la escritora María Moreno en 1984, recuperando la imagen de la madre:

Valdría la pena releer a Alberto Ghiraldo o a Rafael Barret para tener una idea aproximada de qué significaba ser mujer y anarquista en 1919. Sobre todo en este país. En los años de la Semana Trágica. Compañeras anarquistas, maestras anarquistas, periodistas libertarias. (11)

Estos rasgos, Viñas los generalizaba al conjunto de las mujeres como agentes insumisos frente a las instituciones patriarcales. "En un mismo nivel social, cultural, las mujeres tienen mayor lucidez porque tradicionalmente incluso, padecen mayores carencias y por eso tienen una mayor agresividad", le confesaba el escritor a Graciela Speranza (248).

Lo más interesante de su reflexión sobre algunas mujeres -que perspectivas de género mediante resulta esencialista- es que coincide con su lectura de la figura de Eva Perón de principios de los sesenta. Aunque más tarde se mostró distante de ella, en 1962 comenzó a escribir un libro sobre Evita que habría estado a punto de publicarse tres años más tarde en la editorial de Jorge Álvarez. En una entrevista realizada en 1965 por la revista Confirmado, Viñas confesó que se identificaba con Eva Perón porque ambos compartían el mismo resentimiento. El escritor aseguraba que ella "encarnó lo positivo del peronismo, su valor más auténticamente revolucionario. Y lo positivo del peronismo es su negatividad [...] Negatividad en cuanto a negación, lo positivo del peronismo y de Eva Perón fueron sus no" (Confirmado 28).

pueden ser entendidos como alocuciones o escrituras sobre el cuerpo para expresar posiciones y disciplinamientos, así como la posición soberana de los victimarios sobre aquello que consideran sus territorios políticos y corporales. 
Como se ve, sin perder su visión crítica sobre el peronismo, por aquellos años David Viñas se sentía verdaderamente entusiasmado por la figura de Eva Perón, principalmente por su condición de emergente frente a un orden injusto y excluyente ${ }^{8}$. Desde este punto de vista, Yuda, la polemista, la rebelde, la voz de la verdad, el territorio insubordinado, es el espejo anarquista de Evita, aquella muchacha humillada cuyo resentimiento -las palabras son de Viñas $(1965,14$ hipótesis)- era el inicio de una revolución que estaba por hacerse ${ }^{9}$.

Finalmente, hay otro aspecto en Cayó sobre su rostro de particular interés para la coyuntura de 1955 (la novela fue publicada poco antes del golpe de Estado que derrocó a Perón). Gervasio, el hijo bastardo de Antonio Vera, le roba ropas buenas y anda vestido con ellas por el pueblo. Vera protesta pero no hace nada para impedir que ese hijo "chino" haga lo que hace. El muchacho que no tuvo ni la educación ni las oportunidades del hijo matrimonial, toma de su padre lo que le correspondería si fuera un vástago "matrimonial" y que la ley le impedirá tener después de muerto Antonio y, en este sentido, se apropia furtivamente de una herencia. Es un punto relevante si se tiene en cuenta el diálogo de esta narración con la abolición de la forma legal del hijo "ilegítimo" poco antes de la caída de Perón. Y sin dudas con la dimensión política que había tenido la imagen del hijo extramatrimonial para Juan D. Perón y para Evita (ambos provenían de filiaciones irregulares) y de manera figurada, para los sectores sociales excluidos que habían sido la base del peronismo (Cosse 2006). Gervasio y su madre Isabel de acuerdo con su progresivo empoderamiento doméstico y social, ponen de manifiesto la desnaturalización del armado territorial y biopolítico del proyecto liberal: el

8 Al respecto, Aníbal Jarkowski (1997) observa que la construcción de los cuerpos en Los dueños de la tierra confronta con la corporalidad imaginada de Evita: "El cuerpo de Eva Perón fue objeto de numerosas representaciones -literarias, periodísticas, foto y cinematográficas-. El cuerpo, que había sido reducido a enigma, a través de sucesivas transmutaciones se reveló ahora, muy al gusto de los tiempos, bajo la forma de imágenes descarnadas, inocuas. Podrá decirse que resultó un efecto no deseado por sus autores, pero corresponde decir, también, que era un efecto altamente probable en las actuales condiciones de enunciación. Esa desmaterialización del cuerpo -contigua a las estrategias del mundo de la costura- puede ser dramáticamente contrastada con la representación de los cuerpos que aparece en Los dueños de la tierra. Si, como en un río que tuviera dos cauces antagónicos, el cuerpo de Eva Perón fue motivo para operaciones de desvanecimiento, de desrealización, los cuerpos de los obreros fusilados en el Sur aún resisten como evidencia material del curso de la Historia" (112).

9 Sobre ese libro dedicado a Evita solo se conocen las "14 hipótesis de trabajo en torno a Eva Perón" (1965) y las "14 nuevas hipótesis de trabajo en torno a Eva Perón" (1965), publicadas en el semanario uruguayo Marcha. En ellas, Viñas desarrolla con agudeza esa emergencia de Evita y enmarca su trayectoria en la idea de la "revolución inconclusa", y en este sentido, el peronismo sería la propedéutica del cambio social y político. 
dominio de la mujer y el hijo ilegítimos marca el desorden privado y anticipa la caída pública de Vera. En 1955, cuando sale a la calle Cayó sobre su rostro, la familia plebeya y "guacha" de Isabel y Gervasio era la imagen de la fortaleza y de cierto aspecto desestabilizador (desde la perspectiva burguesa) de esas familias postergadas, por entonces indudablemente ligadas al imaginario peronista.

\section{Obras citadas}

Avellaneda, Andrés. El habla de la ideología. Modos de réplica literaria en la Argentina contemporánea. Buenos Aires: Sudamericana, 1983.

Bayer, Osvaldo. La Patagonia rebelde. Buenos Aires: Hyspamérica, 1986.

Confirmado. "David Viñas, frente a Eva Perón: ni obsecuencia ni agravios". Confirmado 11. (1965, 16 de julio): 28.

Cosse, Isabella. Estigmas de nacimiento. Peronismo y orden familiar 1946- 1955. Buenos Aires: Fondo de Cultura Económica, 2006.

Dabove, Juan Pablo. "Eduardo Gutiérrez: narrativa de bandidos y novela popular argentina". Historia crítica de la literatura argentina. Volumen 3: El brote de los géneros. Alejandra Laera Dir. Buenos Aires: Emecé, 2010. 295- 324.

Gamerro, Carlos. "Julio Cortázar, inventor del peronismo". $E l$ peronismo clásico (1945-1955). Descamisados, gorilas y contreras.

Korn, G. Comp. Buenos Aires: Paradiso, 2007. 44-57.

Giorgi, Gabriel. Sueños de exterminio. Homosexualidad y representación en la literatura argentina contemporánea. Rosario: Beatriz Viterbo, 2004.

Iglesia, Cristina, y Julio Schvartman. Cautivas y misioneros. Mitos blancos de la conquista. Buenos Aires: Catálogos, 1987.

Jarkowski, Aníbal. "El otro sur. A propósito de la reedición de Los dueños de la tierra de David Viñas". El Ojo Mocho 11 (1997): 111-112.

Laera, Alejandra. El tiempo vacío de la ficción. Las novelas argentinas de Eduardo Gutiérrez y Eugenio Cambaceres. Buenos Aires: Fondo de Cultura Económica, 2004. Moreno, María. "-Mujeres! dijo David Viñas". Alfonsina 6. 23 de febrero de 1984: 10-12.

Pateman, Carol. "Críticas feministas a la dicotomía público/ privado". Perspectivas feministas en teoría política. Castells, C. Barcelona: Paidós, 1996. 31-52.

Polit Dueñas, Gabriela. Cosas de hombres. Escritores y caudillos en la literatura latinoamericana del siglo XX. Rosario: Beatriz Viterbo, 2008.

Roudinesco, Élisabeth. La familia en desorden. Buenos Aires: Fondo de Cultura Económica, 2010.

Sarlo, Beatriz. La batalla de las ideas (1943-1973). Buenos Aires: Emecé, 2007.

Sebreli, Juan José. Buenos Aires, vida cotidiana y alienación. Buenos Aires: Siglo XX, 1964. 
Segato, Rita. "Territorio, soberanía y crímenes de segundo Estado: la escritura en el cuerpo de las mujeres asesinadas en Ciudad Juárez". Ciudad Juárez: de este lado del puente. Isabel Vericat Comp. México: Instituto Nacional de las Mujeres/ Epikeia, 2004. 75-93.

Speranza, Graciela. Primera persona. Conversaciones con quince narradores argentinos. Buenos Aires: Norma, 1995.

Torre, Juan Carlos Comp. Nueva historia argentina. Tomo VIII: Los años peronistas (1943- 1955). Barcelona: Sudamericana, 2002.

Viñas, David [Pedro Pago]. Mate Cocido. Buenos Aires: Vorágine, 1953.

-. "14 hipótesis de trabajo en torno a Eva Perón". Marcha 1264. 23 de julio de 1965: 23- 24.

-. "14 nuevas hipótesis de trabajo en torno a Eva Perón". Marcha 1270. 3 de septiembre de 1965: 19- 20.

-. Los dueños de la tierra. Buenos Aires: Eudeba, 1966/1958.

—. Cayó sobre su rostro. Buenos Aires: Siglo Veinte, 1975/1955.

-. Indios, ejército y frontera. Buenos Aires: Siglo XXI, 1982.

—.Hombres de a caballo. Buenos Aires: Hyspamérica, 1988/1968. 